\title{
A INTERNET NO BRASIL: A UTILIZAÇÃO POLÍTICA DA TECNOLOGIA DA INFORMAÇÃO.
}

\author{
INTERNET IN BRAZIL: THE POLITICAL USE OF \\ INFORMATION TECHNOLOGY
}

\author{
Lucas Patschiki*
}

\begin{abstract}
RESUMO
A tecnologia da informação é amplamente utilizada como suporte e justificativa de uma ruptura histórica, a passagem para a chamada "era do conhecimento" ou "era da informação", tipo de discurso que se coloca ao lado da ofensiva do capital-imperialismo pela hegemonia ultraliberal, considerada horizonte histórico definitivo, ou "superior" para a humanidade. Neste artigo, iremos explorar como o Estado brasileiro utilizou política e ideologicamente as novas tecnologias para defender a reestruturação produtiva, as privatizações, as expropriações de direitos sociais e a entrada do país na "economia globalizada", tomadas como "necessidades" para a superação deste suposto "atraso" em relação ao novo momento histórico. Focaremos especificamente o Livro verde da sociedade da informação no Brasil (2000), considerado o documento crucial das "diretrizes" para o setor, visando tanto à criação de um consenso entre os seus especialistas quanto ao convencimento do setor usuário.
\end{abstract}

Palavras-chave. Ideologia. Ultraliberalismo. Internet. Brasil.

\begin{abstract}
Information technology is widely used as support and justification for a historical rupture, the passage to the "knowledge age" or "information age", a type of discourse related to the offensive of capital-imperialist by ultraliberal hegemony that is considered the ultimate historical horizon, or "superior" for humanity. This article discusses how the Brazilian state used new technologies politically and ideologically to defend the productive restructuring, the privatization, the expropriations of social rights and the country's entry in the "global economy", taken as "needs" to overcome this alleged "delay "for the new historical moment. The article focuses specifically on the Green Paper on the Information Society in Brazil (2000), considered an essential guideline document for the sector. The document aims to create a consensus among experts and convince the consumption sector.
\end{abstract}

Keywords. Ideology. Ultra-liberalism. Internet. Brazil.

\footnotetext{
* Bacharel em história (UEPG), mestre em história (Unioeste). Este artigo faz parte da dissertação Os leitores da nossa burguesia: O Mídia Sem Máscara em atuação partidária 2002-2011, orientada pelo Dr. Gilberto Grassi Calil e financiada pela Fundação Araucária. <lucas.patschiki@gmail.com> 


\section{Introdução}

Neste artigo, iremos abordar a entrada e a expansão da rede mundial de computadores no Brasil, focando a utilização política da tecnologia como parte do processo de constituição da hegemonia ultraliberal. Nesse sentido, a noção de uma ruptura histórica é crucial para a fundamentação da argumentação ultraliberal, considerando o Brasil um país atrasado diante do novo momento histórico vivido pelos países capitalistas centrais, sendo que todas as reformas pregadas como necessárias por esta noção pobre e acrítica de evolução social. E já assinalemos que a continuidade na defesa deste projeto histórico-social ultrapassa as mudanças nos governos federais desde a década de 1990, seja em seu formato integral, nas gestões do Partido da Social Democracia Brasileiro, ou no formato dito "moderado" das gestões do Partido dos Trabalhadores. Este processo é permeado de conflitos e acordos, tanto intraclasses, tendo o capital financeiro como fração avançada entre a burguesia, quanto pelo convencimento das classes subalternas - sempre associado à coerção para os que não consentem nem ativa nem passivamente. Como visualiza Armando Boito Jr.,

O setor bancário do grande capital e o capital financeiro são os dois únicos setores que ganham com todas as políticas neoliberais [...] Na nossa imagem dos três círculos concêntricos, os interesses dos grandes bancos e do capital financeiro internacional são atendidos em todos os três. O setor industrial do grande capital tem interesse apenas nas duas primeiras políticas e é prejudicado pela abertura comercial e pela desregulamentação financeira, que estão associadas à desindustrialização e à elevação da taxa de juros. O médio capital só tem interesse na primeira política [...] o mesmo ocorre com a burguesia de serviços [...] Se, conforme pretende o imperialismo norte-americano, a desregulamentação financeira e a abertura da economia avançarem ainda mais, poderemos então, acrescentar um quarto e último círculo na nossa figura. Menor e ainda mais restrito, esse novo círculo central contemplaria apenas os interesses do capital financeiro internacional. A política neoliberal no Brasil ainda está longe de ter alcançado todos seus objetivos. O seu horizonte é um colonialismo de um novo tipo. (BOITO JR., 1999, p. 75-76)

Para fim de delimitações teóricas, cabe avisar que consideramos que o neoliberalismo, enquanto categoria, não se faz explicativo para a totalidade dos processos sociais ocorrido nas últimas décadas do século XX. Não se afirma como projeto político-ético dominante por si mesmo, por meio de uma suposta superioridade contida em seus ideólogos, mas porque serviu, e ainda serve, aos interesses do capital-imperialismo, como parte de seu processo histórico de reprodução ampliada (do mesmo modo, não é implementado na realidade segundo um processo homogêneo). É de alto teor descritivo, "aplicando-se a uma política, a uma ideologia e a práticas econômicas que reivindicavam abertamente o ultraliberalismo, porém com forte viés de denúncia", tanto afastando os conceitos clássicos, e é baseado em um "contraste" qualitativo do período histórico anterior, "que reduz a percepção do conteúdo similarmente capitalista e imperialista que liga os dois períodos" (FONTES, 2010, p. 153-54). Do mesmo modo, entendemos o Estado capitalista como uma condensação material de uma relação de forças, ou seja, perpassado pela luta entre as classes e frações de classes (POULANTZAS, 2000, p. 185), o que impede que o tornemos sujeito histórico ou como mero "instrumento". Sua materialidade institucional é marcada pelas relações sociais de produção e pela divisão social do trabalho, contradições que são inseridas em sua própria estrutura. Assim, o Estado também se torna um produtor de hegemonia, ao contrário de leituras cindidas e reducionistas do conceito, que se tornaram correntes por meio de autores como Norberto Bobbio, Perry Anderson ou até mesmo Francisco de Oliveira, em que suas categorias orgânicas são cindidas e até tomadas como antagônicas (BIANCHI, 2008, p. 173). O Estado conta com determinada "autonomia relativa", seja por sua linguagem, tempo e agentes próprios (a elite política e a burocracia), seja por ter o poder de delimitar as formas da exploração, o que só é possível por meio de seu conjunto de aparelhos sustentados pela divisão entre trabalho manual e intelectual, e a atuação orgânica deste último com a dominação política processo de "legitimação de práticas do Estado e de seus agentes como portadores de um saber particular, de uma racionalidade intrínseca... A apropriação da ciência pelo capital se faz certamente na fábrica, mas igualmente pelo Estado" (POULANTZAS, 2000, p. 64). 
Investigaremos aqui uma instância submetida ao Ministério da Ciência e Tecnologia, que sem a participação popular consolidou-se como espaço de embates entre os exploradores do campo, seus especialistas e o Estado - cujo consenso é representado no Livro verde da sociedade da informação no Brasil (2000) através das "diretrizes" para a exploração do setor.

\section{A Internet no Brasil}

No Brasil, a internet chega graças a iniciativas isoladas de pesquisadores universitários pertencentes a instituições como a Fundação de Pesquisa do Estado de São Paulo (Fapesp), o Laboratório Nacional de Computação Científica (LNCC) e a Universidade Federal do Rio de Janeiro (UFRJ) (CARVALHO, 2010), que a partir de 1987 começaram a construir redes que os ligavam ao Bitnet estadunidense - estes pesquisadores e instituições posteriormente irão se intitular como "pioneiros" da rede no país (no mesmo molde dos pesquisadores estadunidenses e europeus), na tentativa de assim se afirmarem como agentes competentes para atuar politicamente em todo o processo (SILVA, 2008, p. 200-10). A rede só irá se tornar objeto de uma política estatal específica em 1990, quando o Ministério da Ciência e Tecnologia lança a Rede Nacional de Ensino e Pesquisa (RNP), que irá construir o primeiro backbone nacional no ano seguinte. Em 1993, este backbone já conectava 11 estados da federação a velocidades mínimas de 9.600 bits por segundo, em grande medida impulsionados por investimentos feitos em relação à rede para organização da Conferência das Nações Unidas sobre o Meio Ambiente e o Desenvolvimento, em 1992, no Rio de Janeiro (mais conhecida como ECO 92). No ano de 1995,

Cerca de 400 instituições de ensino e pesquisa do país se ligaram em rede, incluindo a maioria das universidades e institutos de pesquisa governamentais; Estimativa: 60 mil usuário ativos para uso acadêmico. Segundo as estimativas da época, mais de 10.000 hosts estavam interligados em rede no Brasil. Adotada a premissa de que cada host era utilizado por seis usuários, o número total de usuários ativos era estimado em 60 mil, primariamente para uso acadêmico. (CARVALHO, 2010).
Em abril do mesmo ano, dois anos após a liberação nos Estados Unidos para a exploração comercial, o mesmo ocorre no Brasil. Esta abertura foi considerada estratégica para a ampliação da capacidade da rede:

[...] essa "privatização" da rede, ao contrário do que ocorreu nos Estados Unidos, deu-se, no Brasil, como se fosse algo natural, sem maiores discussões sobre serviço público, universalização ou os termos que tradicionalmente animam o debate político nacional sobre comunicação. (BOLAÑO; CASTAÑEDA, 2010).

Esta abertura foi marcada pela reconfiguração e ampliação do RNP em um backbone de uso misto, comercial e acadêmico, com destaque para a iniciativa privada, já que existiam 11 empresas participando do servidor www da Embratel:

A espinha dorsal da RNP previu pontos de presença em todas as capitais do país, ligação entre as capitais geradoras de maior tráfego a velocidades de 2Mbits/seg (em substituição aos 64Kbits/ seg anteriores) e transformação das ligações de 9.6 Kbits/seg em ligações a $64 \mathrm{~K}$ bits/seg. Para complementar a conectividade na região amazônica, incluindo as cidades Tefé (AM), Cáceres (MT), Santarém e Marabá (PA), Alcântara (MA) e Fernando de Noronha (PE), o MCT estabeleceu um convênio com o Ministério do Meio Ambiente, dos Recursos Hídricos e da Amazônia Legal. (CARVALHO, 2010).

O crescimento posterior da rede é relegado para o mercado, por meio das privatizações e em menor parte pela ampliação dos backbones privados, embora sua estrutura continue vinculada à governança da internet e às políticas públicas de comunicação. Em 2012, existem seis backbones "nacionais": a RNP, a Embratel, o Banco Rural, a Unisys, a Global-One e a IBM (que inicia baseada nos Estados Unidos). Mas como Carlos Afonso aponta, em artigo de 2000, essa ampliação não ocorreu em termos de democratização:

Tal como todos os outros recursos brasileiros, a infraestrutura básica para a disseminação da internet é restrita aos principais municípios e prioriza as camadas mais abastadas da sociedade, tendo como paradigma de utilização o acesso individual que reproduz nossa política de transportes. Tal como esta é feita para quem tem carro, nossas 
"autopistas da informação" são feitas para quem tem microcomputador, linha telefônica e dinheiro para pagar o acesso à internet - ou seja, para os ricos. Dos mais de cinco mil municípios brasileiros, menos de 300 (ou menos de 6\%) conta com a infraestrutura mínima necessária para que possam ser instalados serviços locais de acesso à internet. Os cerca de cinco milhões de usuários da internet no Brasil são menos de $3 \%$ de nossa população. $O$ Brasil é de longe o pior colocado em números per capita de usuários, computadores pessoais, linhas telefônicas e servidores internet (hosts) entre as nove maiores economias do mundo. Os circuitos que conectam os provedores de serviços à internet estão entre os mais caros do mundo, inviabilizando o pequeno provedor de serviços em áreas menos ricas. Não há no país nenhum plano em escala nacional para implantar mecanismos efetivos e abrangentes de democratização de acesso, como telecentros em áreas, cidades ou bairros de menos recursos, conexão maciça de escolas públicas, programas de treinamento básico, pesquisa em alternativas de conexão a baixo custo etc. Um amplo programa poderia ser realizado em menos de dois anos gastando menos de $0,2 \%$ do PIB, mas não há sequer estudos de viabilidade planejados para isso no programa oficial da "sociedade da informação" até agora proposto. (AFONSO, 2000).

Embora distem 12 anos no tempo, essas críticas continuam válidas, mesmo tendo existido uma real ampliação da rede no Brasil, especialmente relativa à banda larga. Os avanços fizeram-se insuficientes e de maneira a agraciar somente interesses mercadológicos: existem grandes áreas no país ainda sem ter disponíveis esses serviços, há apenas 5,8 conexões para cada 100 brasileiros, e os serviços são extremamente caros, 24 vezes mais caros do que nos Estados Unidos. Cerca de 104,7 milhões de brasileiros não acessam a internet (SALVADORI, 2011). A informática, de um modo geral, não é objeto de uso cotidiano de toda a população, seu acesso passa por clivagens classistas, tornando o computador pessoal objeto de fetiche, de desejo. Um estudo particular, da Razorfish, traz indicativos desta leitura, mesmo que utilizando parâmetros de análise social típicos do Banco Mundial: "Dos 28 milhões de lares brasileiros que possuem computadores, $63 \%$ são da classe $\mathrm{C}$, enquanto $23 \%$ pertencem às classes $\mathrm{A}$ e $\mathrm{B}$ e $14 \%$ à classe D. O número de desktops presentes nos lares dessa faixa da população cresceu $15 \%$ en- tre 2006 e 2009", o que aumenta em muito as possibilidades de acesso informativo destas famílias, e que supostamente diminuiria, por assim dizer, o poder da televisão. O que é reafirmado quando analisada a quarta Pesquisa sobre o uso das tecnologias da informação e da comunicação 2008, do CGI.br:

As áreas urbanas de menor poder aquisitivo e a área rural no Brasil representam uma considerável camada social que fica à margem do fenômeno da sociedade da informação e da expansão da infraestrutura das digitais. De acordo com pesquisas do CGI.br, a comparação entre os domicílios nas áreas urbana e rural evidencia uma expressiva diferença na penetração dessas tecnologias: enquanto $28 \%$ dos domicílios nas áreas urbanas possuem computador, nas áreas rurais a penetração dessa tecnologia é de apenas $8 \%$. Com relação ao acesso à internet, enquanto nas áreas urbanas a penetração do acesso chega a $20 \%$ dos domicílios, nas áreas rurais esse percentual cai para apenas $4 \%$. Mesmo se considerarmos somente as áreas urbanas, as variáveis socioeconômicas também revelam as dimensões das desigualdades existentes no país. Nos domicílios urbanos pertencentes às classes $\mathrm{D}$ $\mathrm{e} \mathrm{E}, \mathrm{o}$ acesso à internet é praticamente inexistente (1\%), enquanto nos domicílios de classe A o acesso é praticamente universal (93\%). Esse quadro é ainda agravado pelo fato de a classe A representar apenas $1 \%$ da população urbana e as classes D e E representarem quase um terço dos indivíduos nessas áreas. (BARBOSA; CAPPI; GATTO, 2011).

Não há universalização de acesso à internet para as classes subalternas, a não ser pelas novas exigências sobre a classe trabalhadora urbana no contexto da reestruturação produtiva do capital, que para utilização privada conta com $1 \%$ de acesso. $\mathrm{O}$ campesinato e a população do interior do país são colocados à margem do processo de difusão das novas tecnologias. A única classe capaz de abarcar completamente as novas tecnologias, suas linguagens e possibilidades é a de maior renda, com $93 \%$ de acesso, embora estes dados ainda não nos permitam mensurar as diferenças geracionais.

Em relação ao acesso móvel da rede, "a classe C está usando as tecnologias digitais e móveis para fazer mais do que socializar e se comunicar e, sim, para acessar novas oportunidades educacionais e empresariais. As mídias sociais são as mais acessadas", representando cerca de " $21 \%$ do tempo gasto 
online por meio dos celulares, seguidas por músicas (19\%), esportes (17\%), jogos online (15\%), vídeos online $(12 \%)$ e entretenimento $(9 \%)$ ", enquanto o "acesso a páginas pessoais, chats, compras online e internet banking ficam em $4 \%$ cada um do total de uso da internet via dispositivos móveis" (KNEBEL, 2010). Mas, mesmo que o tempo e o acesso tenham aumentado, a diferenciação crucial explicita-se em relação ao consumo. Segundo levantamento do Ibope, com 2,5 mil pessoas, "a maioria dos consumidores brasileiros que realizam compras na web pertencem às classes A e B e gastam, em média, R\$ 118 por mês", sendo que sozinhas "as classes A e B respondem por $61 \%$ das compras realizadas na internet, seguidas pela classe C, com $35 \%$, e D e E que, juntas, somam apenas 4\%" (AGÊNCIA REUTERS, 2010). Com isso, entendemos que as classes subalternas podem ter agora determinado acesso ao har$d$ ware e à rede, assinalando o aumento vertiginoso da oferta de crédito durante as duas gestões de Luiz Inácio da Silva ("Há oito anos, o crédito disponibilizado em todo o país era de apenas $\mathrm{R} \$ 380$ bilhões. Hoje, o Brasil tem mais de R\$ 1,6 trilhão circulando na economia em forma de empréstimo" GANTOIS, 2010), mas mesmo assim a tecnologia não é parte da vida diária da maioria dos trabalhadores - lembrando que o Brasil é o décimo país com a pior distribuição de renda do planeta. Segundo Mora

Para competir numa economia globalizada, os capitalistas buscam desenvolver máquinas cada vez mais modernas, de alta tecnologia, tarefa reservada aos países centrais. Para a maioria da força de trabalho dos países periféricos, entre os quais o Brasil, está reservada a simples operação das tais máquinas, portanto o trabalho simples. Sob relações de produção capitalistas, o desenvolvimento de máquinas de alta tecnologia e de novas formas de organização do trabalho, o que ocorre é uma desqualificação da maioria dos trabalhadores, e a substituição do antigo trabalhador qualificado por um novo perfil de trabalhador qualificado, apenas com uma instrução básica, que vai no sentido oposto da qualificação mais geral, ou seja, da qualificação para a realização de tarefas mais complexas. Portanto, uma qualificação profissional cujo objetivo é apenas operar máquinas que desenvolvem, elas sim, tarefas complexas. (MORA, 2006)

O uso pleno da tecnologia, e em um sentido mais amplo da ciência em geral, é negado para as classes subalternas, "a afirmação do fim da sociedade do trabalho é a justificativa da apresentação da ciência e da tecnologia como possibilidade superior de resolução das contradições sociais", transformando-a em "racionalidade sempre crescente e independente do confronto entre classes, projetos e concepções de mundo" (DIAS, 2003).

\section{O Livro verde e suas proposições ideológicas}

As ações sobre a internet dentro do aparelho de Estado foram articuladas em diversas instâncias, sendo que uma síntese oficial do processo está no Livro verde da sociedade da informação no Brasil (daqui para diante, $L V$ ), lançado em 2000 pelo Ministério da Ciência e Tecnologia. O livro resulta de discussões de cerca de 150 especialistas e atores políticos (entre empresas, universidades públicas e privadas, instituições estatais e não governamentais), reunidos em 12 grupos de trabalho, cuja coordenação geral foi de Tadao Takahashi. Segundo a biografia de indicados para o Internet Corporation for Assigned Names and Numbers (Icann) entidade responsável pela normatização e o controle global da rede, submissa ao Departamento de Comércio estadunidense de 2003, ele

[...] foi fundador e ex-diretor da Rede Nacional de Ensino e Pesquisa do Brasil (RNP), a internet acadêmica no Brasil. Desde 1999, ele serviu como presidente do Programa Nacional do Brasil para a Sociedade da Informação. Atualmente atua como presidente do Capítulo Brasileiro da Internet Society, na qual ele é um promotor para uma maior participação dos usuários da internet do Brasil nas discussões sobre o futuro da Internet. De 1995-1996 e novamente de 1999-2002, o senhor Takahashi foi membro do Comitê Gestor da Internet no Brasil. Presidente pela América Latina e pelo Nó de Extensão do Caribe, Nó da Força-tarefa das Nações Unidas para TIC, o senhor Takahashi tem uma paixão pelo entendimento das necessidades e interesses dos usuários individuais da internet, especialmente os de comunidades de baixa renda. Trabalhando para trazer acesso à internet para crianças em regiões mais remotas da América Latina, o senhor Takahashi teria negociado com traficantes a permissão para instalar telecentros para acesso à internet nas regiões que controlam. O senhor Takahashi também atuou no Comitê Consultivo de Membros original da Icann em 1998. (ICANN, 2003, tradução nossa). 
As propostas do $L V$ vão além de seu campo específico, visto que para sua implementação desvelam parte de um programa maior, um "novo paradigma", que segundo eles, afetaria "do mesmo modo, regiões, segmentos sociais, setores econômicos, organizações e indivíduos". Nota-se claramente a naturalização da sociedade da informação como superação histórica, baseado em um determinismo tecnológico: "Rapidamente nos adaptamos a essas novidades [tecnológicas] e passamos - em geral, sem uma percepção clara nem maiores questionamentos - a viver na sociedade da informação", caracterizada como "uma nova era em que a informação flui a velocidades e em quantidades há apenas poucos anos inimagináveis, assumindo valores sociais e econômicos fundamentais" (TAKAHASHI, 2000, p. 3-5). Neste ponto, não poderia se fazer mais claro quando afirma que "a sociedade da informação não é um modismo. Representa uma profunda mudança na organização da sociedade e da economia, havendo quem a considere um novo paradigma técnico-econômico". E o marca como "um fenômeno global, com elevado potencial transformador das atividades sociais e econômicas, uma vez que a estrutura e a dinâmica dessas atividades inevitavelmente serão, em alguma medida, afetadas pela infraestrutura de informações disponível". Sendo assim, não poderia deixar de ter consequências totalizantes: "sua dimensão político-econômica, decorrente da contribuição da infraestrutura de informações para que as regiões sejam mais ou menos atraentes em relação aos negócios e empreendimentos", já que "sua importância assemelha-se à de uma boa estrada de rodagem para o sucesso econômico das localidades", que o $L V$ ainda enxerga em sua "marcante dimensão social, em virtude do seu elevado potencial de promover a integração, ao reduzir as distâncias entre pessoas e aumentar o seu nível de informação" (TAKAHASHI, 2000, p. 5). Este tipo de percepção acaba por ser reproduzida em uma série de instâncias do aparelho de Estado brasileiro e, como se vê na citação seguinte, possui uma intenção social clara:

A difusão acelerada das novas tecnologias de informação e comunicação vem promovendo profundas transformações na economia mundial e está na origem de um novo padrão de competição globalizado, em que a capacidade de gerar inovações em intervalos de tempo cada vez mais reduzidos é de vital importância para empresas e países. A utilização intensiva dessas tecnologias introduz maior racionalidade e flexibilidade nos processos produtivos, tornando-os mais eficientes quanto ao uso do capital, trabalho e recursos naturais. Propiciam, ao mesmo tempo, o surgimento de meios e ferramentas para a produção e comercialização de produtos e serviços inovadores, bem como novas oportunidades de investimento. (TAKAHASHI, 2000, p. 17, grifos nossos).

Este tipo de argumentação é tratada em termos de definição de um novo padrão, um novo paradigma, esvaziado de argumentação social, já que determinado pelas novas tecnologias, e assim tratado como inevitável, cabendo à sociedade adaptar-se a este, ou sucumbir, tal qual a URSS para Manuel Castells (2000, p. 47), que simplesmente teria se tornada anacrônica. Como James Petras adverte, "a lógica capitalista é uma lógica linear do capital, que o vê mover-se para cima e para fora sem nenhuma compreensão de sua ascensão e declínio", ainda deixando de situar esta “"lógica' em relação ao papel da política, ideologia e políticas de Estado na fixação dos parâmetros e condições para a acumulação do capital" (PETRAS, 1999, p. 31-32).

Então, esses ideólogos tem que compor sua ruptura para os termos políticos nacionais, por meio das diferenças atribuídas ao desenvolvimento tecnológico nas distintas formações sociais: "a sociedade da informação está sendo construída em meio a diferentes condições e projetos de desenvolvimento social, segundo estratégias moldadas de acordo com cada contexto", sendo que já estariam "transformando as estruturas e as práticas de produção, comercialização e consumo e de cooperação e competição entre os agentes, alterando, enfim, a própria cadeia de geração de valor". Assim sendo "os países economicamente desenvolvidos, bem como boa parte daqueles em vias de desenvolvimento, já adotam políticas e iniciativas voltadas para a sociedade da informação", sendo que ao Estado nacional caberia "acelerar o processo de articulação efetiva de um programa nacional para a sociedade da informação".

Atrelado diretamente à prática política, esse processo é pontuado em seus "sucessos", ou seja, serve de alavanca para levar a prática de políticas de Estado ultraliberais: "a internet brasileira teve 
grande impulso, primeiramente na comunidade cientifica e, logo após, como plataforma de expansão do setor privado, estando aberta também a serviços de natureza comercial desde 1995", associada à "privatização de todo o sistema brasileiro e a criação da Agência Nacional de Telecomunicações (Anatel), fatores que estão permitindo maior e mais rápida disponibilidade de acesso aos meios de comunicação". O que se soma ao fato de que as "atividades comerciais no Brasil que se valem da internet estão ganhando enorme expressão, a ponto de perfazerem praticamente metade do mercado latino-americano, em número de usuários e em volume de transações e negócios", além do que "algumas aplicações de governo têm tido enorme impacto, tanto na melhoria da eficiência interna de funcionamento como na prestação de serviços ao cidadão", e contando com a "base tecnológica instalada no País e um considerável contingente de recursos humanos qualificados, abarcando desde pesquisa e desenvolvimento até fomento a empreendimentos" (TAKAHASHI, 2000, p. 5). Sendo assim,

O país dispõe, pois, dos elementos essenciais para a condução de uma iniciativa nacional rumo à sociedade da informação. E a emergência do novo paradigma constitui, para o Brasil, oportunidade sem precedentes de prestar significativa contribuição para resgatar a sua dívida social, alavancar o desenvolvimento e manter uma posição de competitividade econômica no cenário internacional. A inserção favorável nessa nova onda requer, entretanto, além de base tecnológica e de infraestrutura adequadas, um conjunto de condições e de inovações nas estruturas produtivas e organizacionais, no sistema educacional e nas instâncias reguladoras, normativas e de governo em geral. (TAKAHASHI, 2000, p. 5-6, grifo nosso).

Quando se faz referência à inserção do país na "sociedade da informação", temos de ter em mente a sua abertura às "determinações" desta nova economia, ação coordenada entre a abertura comercial, a chamada reestruturação produtiva na produção na busca pelo fim efetivo dos direitos dos trabalhadores, sobretudo os manuais (quando não sua plena extinção do processo produtivo). Segundo Ronaldo Sardenberg, Ministro da Ciência e Tecnologia do período,
O conhecimento tornou-se, hoje mais do que no passado, um dos principais fatores de superação de desigualdades, de agregação de valor, criação de emprego qualificado e de propagação do bem-estar. A nova situação tem reflexos no sistema econômico e político. A soberania e a autonomia dos países passam mundialmente por uma nova leitura, e sua manutenção que é essencial depende nitidamente do conhecimento, da educação e do desenvolvimento científico e tecnológico [...] Alavancar o desenvolvimento da nova economia em nosso país compreende acelerar a introdução dessas tecnologias no ambiente empresarial brasileiro, objetivo de um dos mais ambiciosos programas do Avança Brasil: o Programa Sociedade da Informação, que resulta de trabalho iniciado em 1996 pelo Conselho Nacional de Ciência e Tecnologia. Sua finalidade substantiva é lançar os alicerces de um projeto estratégico, de amplitude nacional, para integrar e coordenar o desenvolvimento e a utilização de serviços avançados de computação, comunicação e informação e de suas aplicações na sociedade. Essa iniciativa permitirá alavancar a pesquisa e a educação, bem como assegurar que a economia brasileira tenha condições de competir no mercado mundial. (SARDENBERG, 2000, p. 5).

Essas afirmações são baseadas ideologicamente nesse "salto para o futuro" que supostamente ocorreria pela inserção do país na "era da informação". Como afirma Eliane Mora, "o governo e a classe dominante lançam uma cortina de fumaça argumentando que o desemprego é fruto da desqualificação dos trabalhadores e, por isso, se faria necessário um amplo programa de qualificação profissional", sustentando, dessa maneira, "que cada trabalhador esteja mais preparado para competir por um emprego", ou seja, "primeiro o governo tenta responsabilizar o próprio trabalhador por estar desempregado ou com o emprego sob risco. Depois, tenta vender a ilusão de que, com mais qualificação, fica mais fácil garantir emprego". A autora deixa isso em termos claros: "mentiras óbvias, pois, se assim fosse, nos países centrais não haveria taxas de desemprego tão altas, posto que o nível de escolaridade e qualificação profissional são muito superiores aos dos países periféricos", concluindo que, se "requalificação profissional ou a educação são formas eficazes para combater o desemprego implica a ilusão de que estas poderão criar os postos de trabalho fechados pelo capital" (MORA, 2006). 
Francisco de Oliveira sintetiza esse processo que associa nossa dependência tecnológica com os países capital-imperialistas centrais e a dissolução do tempo do trabalho, da superexploração por meio do que chama de "trabalho abstrato virtual":

Avassalada pela terceira revolução industrial, ou molecular-digital, em combinação com o movimento da mundialização do capital, a produtividade do trabalho dá um salto mortal em direção à plenitude do trabalho abstrato. Em sua dupla constituição, as formas concretas e a "essência" abstrata, o consumo das forças de trabalho vivas encontrava obstáculos, a porosidade entre o tempo de trabalho total e o tempo de trabalho da produção. Todo o crescimento da produtividade do trabalho é a luta do capital para encurtar a distância entre essas duas grandezas. Teoricamente, trata-se de transformar todo o tempo de trabalho em trabalho não pago; parece coisa de feitiçaria, e é o fetiche em sua máxima expressão. Aqui, quase se fundem mais-valia absoluta e relativa: absoluta porque o capital usa o trabalhador quando necessita dele, relativa porque isso é possível somente devido à enorme produtividade. A contradição: a jornada da mais-valia relativa deveria ser de diminuição do trabalho não pago, mas é o seu contrário. Então, graças à produtividade do trabalho, desaparecem os tempos de não trabalho: todo o tempo de trabalho é tempo de produção. Os serviços são o lugar da divisão social do trabalho onde essa ruptura já aparece com clareza. Cria-se uma espécie de "trabalho abstrato virtual". As formas "exóticas" desse trabalho abstrato virtual estão ali onde o trabalho aparece como diversão, entretenimento, comunidade entre trabalhadores e consumidores: nos shopping centers. Mas é na informação que reside o trabalho abstrato virtual. $\mathrm{O}$ trabalho mais pesado, mais primitivo, é também lugar do trabalho abstrato virtual. Sua forma, uma fantasmagoria, um não lugar, um não tempo, que é igual a tempo total. Pense-se em alguém em sua casa, acessando sua conta bancária pelo seu computador, fazendo o trabalho que antes cabia a um bancário: de que trabalho se trata? (OLIVEIRA, 2010).

Retornando para as premissas ideológicas do $L V$, todo esse processo esteve atrelado à "necessidade" de privatizar completamente o setor, considerado em termos evolutivos banais: "o longo período de crise na evolução brasileira no setor se estendeu até 1995, quando o governo federal propôs novas diretrizes, que seriam sancionadas em uma nova Lei de
Telecomunicações", que priorizou a "privatização do sistema Telebrás; concepção de um regime de duopólio para todos os serviços durante um período de transação até o final de 2001; competição crescentemente ampla a partir de 2002" (TAKAHASHI, 2000, p. 121). Esse processo de desmonte das estatais, justificada pelo símbolo de "modernização" (GADELHA, 2010), articulou-se com diversas proposições, sendo mais significativa a Lei de Informática (Lei 5.804), do governo Fernando Collor. Essa lei acabava com o poder da Secretaria Especial de Informática (SEI), criada em 1979 para "militarizar a questão da informática como forma de garantir o protecionismo nacional", de controlar a importação do setor, assim acabando com a reserva de mercado nacional, com os incentivos fiscais, e diminuindo a porcentagem de acionistas (entre físicos e jurídicos de capital votante) brasileiros para que a empresa fosse considerada de capital nacional de 70 para 51\% (ZAVERUCHA, 2000, p. 64-65). Augusto César Gadelha Vieira, secretário de Política da Informática do Ministério da Ciência e Tecnologia, e um dos coordenadores do Comitê Gestor da Internet no Brasil (CGI.br) espaço de consenso entre representantes dos exploradores do setor, do Estado e do "terceiro setor" dentro do aparelho de Estado brasileiro, faz uma síntese desse processo na revista de 15 anos do comitê:

Iniciamos na década de 1980 com a criação de redes acadêmicas que, apesar das dificuldades impostas pelo monopólio da Embratel no transporte internacional de dados (as denominadas transfronteiras), lograram se conectar às redes acadêmicas dos Estados Unidos no final da década. Essas redes acadêmicas foram as precursoras da internet no país [...] No início da década de 1990, com a criação da RNP por iniciativa do MCT, consolidada pela equipe comandada por Tadao Takahashi, e com o estabelecimento da primeira conexão com protocolo TCP/IP, pela equipe liderada por Demi Getschko na Fapesp, o Brasil começou efetivamente a participar da internet [...] O terceiro setor no Brasil, sob a liderança de Betinho, contribui para a expansão de nossa rede primordial, ao usá-la (apesar das dificuldades de então) para divulgar, pelo mundo todo, a ECO-92 realizada no Rio de Janeiro [...] Em seguida vieram os empreendedores que perceberem as oportunidades de novos negócios de provimento de acesso e de conteúdos para a internet. A participação mais ampla 
da sociedade, em particular das empresas, se dá com a disseminação do uso da Web. Até meados de 1995, todos esses atores estavam conversando, mas isoladamente em suas próprias comunidades. $\mathrm{O}$ governo, na recém-inaugurada Nova República, percebeu a importância da rede e a mobilização crescente criada em torno dela. (GADELHA, 2010).

A lógica da acumulação e da exploração permeia a disseminação e popularização da internet no Brasil, servindo como suporte, como justificativa e processo pela implementação da hegemonia ultraliberal. A mesma Lei de Informática de Collor, mesmo analisada dentro do desastre de seu plano econômico e dos casos de corrupção de seu governo, é considerada um marco decisivo para o país. José Carlos Cavalcanti, professor de economia da Universidade Federal de Pernambuco (UFPE), no lançamento do grupo de trabalho de economia de redes pelo CGI.br, em 1995, do qual é um dos coordenadores, explicita isso:

A missão deste GT está segmentada em duas dimensões: a macroeconômica e a microeconômica. $\mathrm{Na}$ dimensão macro, o GT procura dotar a internet/br de instrumentos para que ela se coloque a serviço da definição de um modelo brasileiro de reestruturação industrial, em um contexto de abertura e integração econômicas. Na dimensão micro, o GT procura dotar a internet/br de instrumentos da teoria e prática econômicas que deem autossustentação econômico-financeira (dentro dos critérios de eficiência e equidade) aos seus objetivos primordiais de: cobertura nacional e ampla capilaridade; vasta gama de aplicações, e baixo custo para o usuário final, com papel prioritário para a livre iniciativa. (CAVALCANTI, 2010).

Esse trecho sintetiza como se dá a relação entre democratização como acesso universal à internet no Brasil, pensado como direito social, e democracia como possibilidade de escolha dos representantes dos exploradores, as grandes empresas fornecedoras ou operadoras de tecnologia de informação, sem dúvida os "usuários finais" interessados na reestruturação industrial.

\section{Considerações finais}

Como visto, em nenhum momento se esconde sob qual perspectiva política, econômica e social essa tecnologia deve servir. Novamente assinalemos, esse processo é sempre reafirmado em termos de determinação histórica, no qual somente nos caberia como papel a sujeição. Segundo Francisco de Oliveira, o capitalismo brasileiro "perdeu a capacidade de escolha, de 'seleção', e por isso é uma evolução truncada: como sugere a literatura da economia da tecnologia, o progresso técnico é incremental", baseado em uma escala "evolucionista, neoschumpeteriana", já que essa "revolução molecular-digital anula a fronteira entre ciência e tecnologia: as duas são trabalhadas agora num mesmo processo, numa mesma unidade teórico-metodológica. Faz-se ciência fazendo tecnologia e vice-versa". E já que o progresso se faz "incremental, ele depende fundamentalmente da acumulação científico-tecnológica anterior. Enquanto o progresso técnico da Segunda Revolução Industrial permitia saltar à frente, operando por rupturas sem prévia acumulação técnico-científica", pois tratava-se "de conhecimento difuso e universal", este "novo conhecimento técnico-científico está trancado nas patentes, e não está disponível nas prateleiras do supermercado das inovações. E ele é descartável, efêmero". Isso tem consequências drásticas sobre os países periféricos, pois "essa combinação de descartabilidade, efemeridade e progresso incremental corta o passo às economias e sociedades que permanecem na rabeira do conhecimento técnico-científico" (OLIVEIRA, 2010).

Do que se extraem duas implicações que já se tornaram realidades em termos diretamente relacionados à acumulação capitalista no país (pensada em processo, não como um único momento inicial do capitalismo). A primeira refere-se ao eterno atraso na produção tecnológica, podendo apropriar-se da cópia, do "descartável, mas não copiar a matriz da unidade técnico-científica". A segunda é que essa acumulação entra na sincronização da produção ditada pelos países capitalistas centrais, sendo "que a acumulação que se realiza em termos de cópia do descartável, também entra em obsolescência acelerada, e nada sobra dela, ao contrário da acumulação baseada na Segunda Revolução Industrial", exigindo maior esforço e investimento, maiores que os capazes de serem feitos pelas forças internas, "o que reitera os mecanismos de dependência financeira externa. Mas o resultado fica sempre aquém do esforço". Como constata o sociólogo, essa contradição torna-se mais violenta "porque a mundializa- 
ção introduz aumento da produtividade do trabalho sem acumulação de capital, justamente pelo caráter divisível da forma técnica molecular-digital, do que resulta a permanência da má distribuição da renda" (OLIVEIRA, 2010).

Observa-se que o chão social das ideologias é mais próximo das relações sociais que as sustentam do que imaginam alguns teóricos. Sua relação é de organicidade com a estrutura, relação que mesmo mediada (ou seja, possuindo dada autonomia) é determinada por sua conexão com a estrutura:

Entre estrutura e superestrutura existe, portanto, um nexo necessário e vital. Por isso mesmo, conforme a visão gramsciana - e este é um de seus pontos mais centrais -, as possibilidades de que as superestruturas se constituam em resultante mecânica do que os homens vivenciam no plano estrutural representam uma séria distorção, posto que a articulação entre os planos aponta inclusive para a possibilidade de que ocorra certa autonomia das relações superestruturais, conforme a conjuntura histórica, as correlações de forças e o grau de organização de uma formação social. Tal fato evidentemente não descarta, mas reforça a mencionada articulação entre os planos, porque essa relação de reciprocidade entre forças materiais e ideologias aponta para uma possibilidade concreta de o desenvolvimento histórico das formações sociais capitalistas ser uma resultante da simultaneidade entre instrumentos de coerção, persuasão das forças político-sociais em disputa pela hegemonia político-social e alterações concretas nas forças materiais de produção social. (NEVES; SANT'ANNA, 2005, p. 21).

Como visto, o locus de poder responsável pela regulação e estabelecimento de diretrizes estatais para o uso da rede que pode ser expandido para o CGI.br (PATSCHIKI, 2012, p. 83-100), faz-se mais um espaço de embates e construção do consenso entre os exploradores do setor, incrustado na ossatura material do Estado. "Se o processo de acumulação do capital pauta doravante diretamente a ação do Estado, ele só se traduz em seu seio quando articulado e inserido na sua política de conjunto. Toda medida econômica do Estado tem portanto um conteúdo político", tanto em um "sentido geral de uma contribuição para a acumulação do capital e para a exploração" quanto "no sentido de uma necessária adaptação à estratégia política da fração hegemônica". As- sim, "não apenas as funções político-ideológicas do Estado são doravante subordinadas a seu papel econômico, como também as funções econômicas estão doravante diretamente encarregadas da reprodução da ideologia dominante" (POULANTZAS, 2000, p. 170-71). É o Estado dando forma para a exploração em um novo setor do capital, potencializando a expansão da fração de classe em sua gerência como parte de um processo mais amplo, nacional e naturalizado como consequência lógica, racional, de novas tecnologias, atrelando-as às mudanças no mundo do trabalho e dando ao processo uma aparência de igualdade, de democratização, na busca pela universalização do conhecimento.

É crucial que se discuta a falsa percepção de que a tecnologia é neutra, ou que a internet se faz espaço público. Trata-se de um espaço de embates e organização, mas cuja apropriação consequente pelas classes subalternas em luta tem de estar submetida à análise concreta das relações de forças que a compõem.

\section{Referências}

AFONSO, C. A. Internet no Brasil: o acesso para todos é possível? Disponível em: http://reseau.crdi.ca/uploads/userS/10245206800panlacafoant.pdf. Acesso em: 10 outubro 2010.

AGÊNCIA REUTERS. Classes A e B lideram e-commerce brasileiro. Disponível em: http://info.abril.com.br/ noticias/mercado/classes-a-e-b-lideram-e-commercebrasileiro-08122010-28.shl. Acesso em: 05 janeiro 2011.

ALMEIDA, A. P. S. De. Os métodos de ensino para uma Sociedade da Informação. Revista Textos de la CiberSociedad, n. 8, 2008. Disponível em: http://www. cibersociedad.net. Acesso em: 08 maio 2012.

\begin{abstract}
ANDES-SN. Educação à distância, abertura do mercado educacional ao capital estrangeiro e ampliação espúria da educação superior: uma crítica à política de EAD do governo Lula da Silva. Disponível em: http://www.andes. org.br/imprensa/Uploads/Circ290-05.zip. Acesso em: 13 novembro 2010.
\end{abstract}

ASSOCIAÇÃO BRASILEIRA DE USUÁRIOS DE NUMERAÇÃO IP \& ASSINANTES DE DOMÍNIOS. Abusando.org: direito e justiça digital. Disponível em: http://www.abusando.org/nada/inicio.html. Acesso em: 03 maio 2012.

. Lista dos membros do Comitê Gestor Internet

Brasil. Disponível em: http://www.abusando.info/ denuncias/comitegestor.html. Acesso em: 10 outubro 2010. 
BARBOSA, A. F.; CAPPI, J.; GATTO, R. Os caminhos para 0 avanço do governo eletrônico no Brasil. Disponível em: http://www.cgi.br/publicacoes/artigos/artigo63.htm. Acesso em: 04 abril 2011.

BIANCHI, A. O laboratório de Gramsci: filosofia, história e política. São Paulo: Alameda, 2008.

BOITO JR., A. Política neoliberal e sindicalismo no Brasil. São Paulo: Xamã, 1999.

BOLAÑO, C. R. S.; CASTAÑEDA, M. V. A economia política da internet e sua crise. Disponível em http:// www.eca.usp.br/alaic/material\%20congresso\%202002/ congBolivia2002/trabalhos $\% 20$ completos $\% 20$ Bolivia $\% 20$ 2002/GT\%20\%202\%20\%20cesar\%20bolano/Marcos\%20 Bolano.doc. Acesso em: 01 setembro 2010.

CARVALHO, M. L. B. de. História da internet no Brasil. Disponível em: http://homepages.dcc.ufmg.br/ mlbc/ cursos/internet/historia/Brasil.html, Acessao em: 20 outubro 2010.

CASTELLS, M. A sociedade em rede. A era da informação: economia, sociedade e cultura. Volume 1. São Paulo: Paz e Terra, 2000.

CavalCanTI, J. C. Economia de redes. Disponível em: http://www.cgi.br/publicacoes/artigos/artigo1.htm. Acesso em: 04novembro 2010.

CGI.BR. CGI.br: uma história de sucesso. Disponível em: http://www.cgi.br/publicacoes/revista/edicao03/cgibrrevistabr-ed3.pdf. Acesso em: 03 janeiro 2012.

. Sem sair de casa. CGI.br. Disponível em: http:// www.cgi.br/publicacoes/revista/edicao03/cgibr-revistabred3.pdf, Acesso em: 03 janeiro 2012.

Grupos de trabalho: GTER. Disponível em: http://www.nic.br/grupo/gter.htm. Acesso em: 20 dezembro 2010.

. Grupos de trabalho: GTS. Disponível em: http:// www.nic.br/grupo/gts.htm. Acesso em: 13 dezembro 2010.

Histórico. Disponível em: http://www.cgi.br/

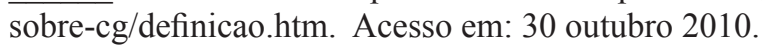

. Lista dos membros do Comitê Gestor Internet Brasil. Disponível em: http://www.abusando.info/ denuncias/comitegestor.html. Acesso em: 10 outubro 2010.

DECLARAÇÃO de Getschko. In. CGI.BR. CGI.br: uma história de sucesso. CGI.br. Disponível em http://www.cgi. br/publicacoes/revista/edicao03/cgibr-revistabr-ed3.pdf, acessado em 03.01.12.

DIAS, E. Reestruturação produtiva: forma atual da luta de classes. Outubro. n. 1, 2003. Disponível em: http://www. revistaoutubro.com.br/edicoes/01/out01_03.pdf. Acesso em: 16 outubro 2011.
FONTES, V. O Brasil e o capital imperialismo: teoria e história. Rio de Janeiro: EPSJV/UFRJ, 2010.

GADELHA, A. C. Editorial. CGI.br. n. 3. Disponível em: http://www.cgi.br/publicacoes/revista/edicao03. Acesso em: 18 novembro 2010.

GANTOIS, G. Aumento do crédito e do consumo são heranças de Lula. Governo aproveitou os anos dourados da economia mundial, mas deixa inflação em risco. 31.12.2010. Disponível em: http://noticias.r7.com/economia/noticias/ aumento-do-credito-e-do-consumo-sao-herancas-delula-20101231.html. Acesso em: 13 março 2011.

ICANN. Nominees of the 2003 Nominating Committee to the ICANN board, GNSO council, and At-Large advisory committee. 16.06.03. Disponível em: http://www. icann.org/en/committees/nom-comm/nominee-biographies16jun03.htm. Acesso em: 05 dezembro 2011.

KNEBEL, P. Estudo ressalta a nova classe média digital no país. Jornal do Comércio, 01.11.2010. Disponível em: http://jcrs.uol.com.br/site/noticia.php? $\operatorname{codn}=45175$. Acesso em: 05 janeiro 2011.

MORA, E. A. Tensões na formação profissional da CUT e na disputa dos fundos públicos. Outubro, n. 6, 2006. Disponível em: http://www.revistaoutubro.com.br/ edicoes/06/out6_06.pdf. Acesso em: 10 novembro 2010.

NEVES, L. M. W.; SANT'ANNA R. Introdução: Gramsci, o Estado educador e a nova pedagogia da hegemonia. In. NEVES, L. M. W. A nova pedagogia da hegemonia: estratégias do capital para educar o consenso. São Paulo: Xamã, 2005.

OLIVEIRA, F. O ornitorrinco. Disponível em: http:// afoiceeomartelo.com.br/posfsa/Autores/Oliveira, $\% 20$ Francisco/Francisco\%20de\%20Oliveira\%20-\%20O\%20 Ornitorrinco.rtf. Acesso em: 13 dezembro 2010.

PATSCHIKI, L. Os litores da nossa burguesia: o Mídia Sem Máscara em atuação partidária (2002-2011). Dissertação de Mestrado. Marechal Cândido Rondon: UNIOESTE, 2012.

PETRAS, J. Armadilha neoliberal e alternativas para a América Latina. São Paulo: Xamã, 1999.

POULANTZAS, N. O Estado, o poder, o socialismo. São Paulo: Paz e Terra, 2000.

RIPAMONTE, N. Os riscos do grande avanço na democratização da internet. Disponível em: http:// www.cbeji.com.br/br/downloads/secao/O\%20Comitê $\% 20$ Gestor\%20da\%20Internet $\% 20$ do $\% 20$ Brasil $\% 20$ 01_07_04[1].doc. Acesso em: 10 outubro 2010.

SALVADORI, F. Banda larga no Brasil é cara e ruim; entenda. Galileu. Disponível em http://revistagalileu.globo. com/Revista/Common/0,,EMI138571-17770,00-BANDA +LARGA+NO+BRASIL+E+CARA+E+RUIM+ENTEN DA.html. Acesso em: 03 maio 2011. 
SARDENBERG, R. M. Apresentação. In. TAKAHASHI, T. (Org.). Sociedade da informação no Brasil: livro verde. Brasília: Ministério da Ciência e da Tecnologia, 2000.

SILVA, M. T. C. A geopolítica da rede e a governança global de internet a partir da cúpula mundial da sociedade da informação. Tese de Doutorado. São Paulo: USP, 2008.

TAKAHASHI, T. (Org.). Sociedade da informação no Brasil: livro verde. Brasília: Ministério da Ciência e da Tecnologia, 2000.

VELOSO, E. M. Legislação sobre internet no Brasil. Consultoria Legislativa da Câmara de Deputados, 05.09. Disponível em: http://www2.camara.gov.br/documentose-pesquisa/fiquePorDentro/temas/regulacao_da_internet/ 2009-6863\%20Estudo\%20Internet.pdf. Acesso em: 12 dezembro 2010.

ZAVERUCHA, J. Frágil democracia: Collor, Itamar, FHC e os militares (1990-1998). Rio de Janeiro: Civilização Brasileira, 2000.

Recebido para publicação: 15/05/2012

Aceito para publicação: 27/05/2012 